\title{
Inducción de la degradación de lignina de paja de trigo en aromáticos por Aspergillus spp. y Penicillium chrysogenum
}

\section{Wheat straw lignin degradation induction to aromatics by por Aspergillus spp. and Penicillium chrysogenum}

\author{
Baltierra-Trejo Eduardo ${ }^{1,2}$, Silva-Espino Eliseo ${ }^{1}$, Márquez-Benavides Liliana ${ }^{1}$, Sánchez-Yáñez Juan Manuel ${ }^{2 *}$
}

\section{Datos del Articulo \\ ${ }^{1}$ Manejo de Residuos Sólidos y Medio Ambiente, Instituto de Investigaciones Agropecuarias y Forestales (IIAF) de la Universidad Michoacana de San Nicolás de Hidalgo. \\ Av. San Juanito Itzicuaro S/N. Col. San Juanito Itzicuaro Morelia, Mich. 58302 México. Tel. +52(443)334-04 75 ext. 116. \\ ${ }^{2}$ Microbiologia Ambiental, Instituto de Investigaciones Químico-Biológicas (IIQB) de la Universidad Michoacan de San Nicolás de Hidalgo (UMSNH). Edif. B-3 Ciudad Universitaria, Av. Francisco J. Mujica S/N Col. Felicitas del Río, Morelia Mich., 58040 México. Tel. +52 (443) 3223500 ext. 4240 . \\ *Dirección de contacto: Laboratorio de Microbiología Ambien- tal del Instituto de Investigaciones Químico-Biológicas (IIQB) de la Universidad Michoacana de San Nicolás de Hidalgo (UMSNH). Edif. B-3 Ciudad Universitaria, Av. Francisco J. Mujica S/N Col. Felicitas del Río, Morelia Mich., 58040 México. Tel. +52 (443) 3223500 ext. 4240 \\ Juan Manuel Sánchez-Yáñez E-mail address :syanez@umich.mx}

\section{Palabras clave:}

Residuo - agrícola,

lacasa,

aromático.

J. Selva Andina Res. Soc. 2016; 7(1):10-19.

\section{Historial del artículo.}

Recibido junio, 2015

Devuelto enero 2016

Aceptado enero, 2016.

Disponible en línea, febrero, 2016.

Editado por:

Selva Andina

Research Society

\section{Resumen}

La paja de trigo es un desecho agrícola recalcitrante, su eliminación por incineración contamina el ambiente. Se ha investigado el aprovechamiento de sus componentes estructurales: celulosa, hemicelulosa a excepción de la lignina por ser la porción recalcitrante. La lignina residual de paja de trigo (LIREPATO) tiene valor potencial biotecnológico si es degradada en aromáticos. Como alternativa, los hongos mitospóricos ligninolíticos poco se han investigado, a pesar de que degradan la LIREPATO en medio de cultivo mineral en un tiempo relativamente corto comparado con lo reportado con los basidiomicetos. El objetivo de esta investigación fue analizar en Aspergillus spp y Penicillium spp en la degradación de LIREPATO como única fuente de carbono en la generación de aromáticos. La degradación de la LIREPATO en aromaticos se realizo lacasa, lignina peroxidasa y manganeso peroxidasa. Los aromáticos generados se identificaron por cromatografía de gases. Los resultados señalan que Penicillium chrysogenum degradó la LIREPATO con hasta un $34.8 \%$ en 28 días de incubación. La actividad lacasa fue la mayor con $111 \mathrm{U} \mathrm{L}^{-1}$ en 7 días, menor tiempo a lo reportado en basidiomicetos y sin la adición una fuente de carbono adicional para inducirla. Aspergillus ssp y Penicilium spp generaron guayacol, vainillina, ácidos hidroxibenzoico, vainillínico, siríngico, y ferúlico con producción máxima por semana de 3.5, 3.3, 3.2, 3.3, 10.1 y $21.9 \mathrm{mg} \mathrm{mL}^{-1}$ respectivamente

(C) 2016. Journal of the Selva Andina Research Society. Bolivia. Todos los derechos reservados.

\section{Abstract}

Wheat straw is a recalcitrant agricultural waste; incineration of this material represents an important environmental impact. Different reports have been made regarding the use of the structural components of wheat straw, i.e. cellulose, hemicellulose and lignin; however, lignin has been less exploited because it is largely considered the recalcitrant part. Residual wheat straw lignin (REWSLI) has a potential biotechnological value if depolymerization is attained to produce aromatics. Ligninolytic mitosporic fungus represent an alternative where very little research has been done, even though they are capable of depolymerize REWSLI in simple nutritional conditions in relatively short periods, when compared to basidiomycetes. The aim of this research was to study the depolymerization activity of Aspergillus spp and Penicillium spp on semipurified REWSLI as the sole carbon source to produce aromatics. The depolymerization capacity was determined by the activity of the laccase, lignin peroxidase and manganese peroxidase enzymes. The generated aromatics derived from the REWSLI depolymerization were 
identified by gas chromatography. Obtained results revealed that Penicillium chrysogenum depolymerized the lignin material by $34.8 \%$ during the 28 -day experimentation period. Laccase activity showed the largest activity with $111 \mathrm{U} \mathrm{L}^{-1}$ in a seven-day period, this enzyme induction was detected in a smaller period than that required by basidiomycetes to induce it. Moreover, the enzymatic activity was produced without the addition of an extra carbon source as metabolic inductor. Aspergillus spp and Penicillium spp generated guaiacol, vanillin, and hydroxybenzoic, vanillinic, syringic and ferulic acid with a maximum weekly production of 3.5, 3.3, 3.2, 3.3, 10.1 and $21.9 \mathrm{mg} \mathrm{mL}^{-1}$, respectively.

(c) 2016. Journal of the Selva Andina Research Society. Bolivia. All rights reserved.

\section{Introducción}

El Triticum aestivum (trigo) es el cultivo más extendido a nivel mundial, sembrado en 115 países con una producción de $675 \times 10^{9} \mathrm{~kg}$ año ${ }^{-1}($ Kim \& Dale 2004, FAO 2012). Como resultado se genera como subproducto un estimado de $877 \times 10^{9} \mathrm{~kg}$ de paja residual (Talebnia et al. 2010), cuya disposición final es comúnmente la incineración "in situ", con un impacto ambiental negativo, por la emisión de partículas en suspensión $\left(\mathrm{PM}_{10}\right)$ y gases $\mathrm{CO}, \mathrm{CO}_{2}$, $\mathrm{NO}_{2}, \mathrm{SO}_{2}, \mathrm{O}_{3}$ (Li et al. 2008, Quintero-Núñez \& Moncada-Aguilar 2008). La paja de trigo está constituida por remanentes estructurales de la pared celular vegetal: celulosa (39\%), hemicelulosa (38.7\%) lignina (17\%) (Xu et al. 2006). La celulosa, hemicelulosa son polímeros de azúcares aprovechados en la producción de bioetanol (Dashtban et al. 2010), biohidrógeno (Quéméneur et al. 2012) y alimento para rumiantes (Tuyen et al. 2012), sin embargo la lignina es un componente recalcitrante y residual para la explotación de la paja de trigo.

La lignina es un polímero heterogéneo constituido por 3 unidades de aromáticos derivados del alcohol $p$-hidroxicinamilico: el coniferilico, el sinapilico y el $p$-coumarilico, precursores a su vez del guayacol, el siringol y el hidroxifenol, unidas por enlaces arileter $(\beta-\mathrm{O}-4)$, aril-aril y carbono-carbono $\left(\mathrm{C}_{\alpha}-\mathrm{C}_{\beta}\right)$ principalmente (Dekker et al. 2002, Martínez et al. 2005).

No existen reportes en la literatura para la explotación biotecnológica de la lignina residual de paja de trigo (LIREPATO), sin embargo es aprovechable si se degrada en aromáticos de valor biotecnológico. Una alternativa para la degradación de la LIREPATO son los métodos químicos, con la desventaja de que son costosos y contaminantes. Una opción ambientalmente segura, reportada en la literatura en otros residuos lignocelulósicos, son los basidiomicetos, que si bien son efectivos en la degradación de lignina, su tiempo de generación es relativamente lento (semanas). Una alternativa menos explorada son Aspergillus spp. y Penicillium spp. ejemplo de hongos mitospóricos ligninolíticos (HML) cuya investigación preliminar reportó que tienen una capacidad similar a los basidiomicetos, pero con tiempo de generación menor (días) (Safari-Sinegani et al. 2005, Zeng et al. 2006, Chang et al. 2012). Aspergillus spp y Penicillium spp. inducen tres enzimas para la degradación de la lignina: la lacasa (Lac), la lignina peroxidasa (LiP) y la manganeso peroxidasa (MnP) (Dashtban et al. 2010). Estas participan en la ruptura de las uniones $\mathrm{C}_{\alpha}-\mathrm{C}_{\beta}$ y $\beta$-O4 con la formación de monómeros aromáticos, seguido por la oxidación de los grupos funcionales y 
finalmente de la ruptura de los anillos aromáticos (Ferraz \& Durán 1995). Los aromáticos de la LIREPATO son útiles para usarse como fuente de materia prima para la obtención de combustibles como bioetanol y biogás (Sánchez 2009) o en aromáticos de interés para la industria alimenticia y farmacéutica como la vainillina, guayacol, tirosina, ácido ferúlico, gallico, hidroxibenzoico, siríngico, vainillínico, etc., (Buranov \& Mazza, 2008, Widsten $\&$ Kandelbauer 2008). Con base a lo anterior el objetivo de esta investigación fue analizar en Aspergillus spp y Penicillium chrysogenum en la degradacion de la LIREPATO como única fuente de carbono en la generación de aromaticos.

\section{Materiales y métodos}

Selección y activación de Aspergillus y Penicillium. De la colección del Laboratorio de Microbiología Ambiental del Instituto de Investigaciones QuímicoBiológicas de la UMSNH se analizaron las cepas de Penicillium chrysogenum AT3 y AT4, así como Aspergillus fumigatus AT11 y A. tubigensis AT12. Para semipurificar la LIREPATO e hidrolizar una fracción de la celulosa y las hemicelulosas se sometió la paja de trigo a tratamiento ácido-térmico. Para ello se molió y tamizó en malla de $0.0841 \mathrm{~mm}$, se le adicionó por aspersión ácido acético $\left(\mathrm{CH}_{3}-\mathrm{COOH}\right)$ al 10\% (v/v)/30 min en proporción 1:2 (p/v), se neutralizó con hidróxido de sodio $(\mathrm{NaOH})$ al $10 \%$ (p/v), se sometió a $120{ }^{\circ} \mathrm{C}$ por $60 \mathrm{~min}$, se lavó con agua destilada y se secó a $70{ }^{\circ} \mathrm{C}$ por 24 h. Los HML se activaron en medio agar-LIREPATO cuya composición fue $\left(\mathrm{g} \mathrm{L}^{-1}\right)$ : LIREPATO 10, peptona de caseína 5, extracto de levadura $1.3, \mathrm{~K}_{2} \mathrm{HPO}_{4} 0.17$, $\mathrm{KH}_{2} \mathrm{PO}_{4} 2.61, \mathrm{MgSO}_{4} 1.5, \mathrm{NaCl} 0.9, \mathrm{CuSO}_{4} 0.05$, se adicionó azul de bromotimol $10 \mathrm{ppm}, 2.5 \mathrm{~mL}$ de solución detergente al $10 \%(\mathrm{p} / \mathrm{v})$, agar $18 \mathrm{~g} \mathrm{~L}^{-1}$ y 1
$\mathrm{mL} \mathrm{L}^{-1}$ de solución de oligoelementos que se preparó con $\left(\mathrm{g} \mathrm{L}^{-1}\right): \mathrm{H}_{3} \mathrm{BO}_{3} \quad 2.86, \mathrm{ZnSO}_{4}-7 \mathrm{H}_{2} \mathrm{O} \quad 0.22$, $\mathrm{MnCl}_{2}-7 \mathrm{H}_{2} \mathrm{O}$ 1.81, $\mathrm{KMnO}_{4}$ 0.09. Finalmente se ajustó el pH del agar LIREPATO a 5.5 y se esterilizó a $121{ }^{\circ} \mathrm{C}$ durante $20 \mathrm{~min}$. Los HML se incubaron a $30{ }^{\circ} \mathrm{C}$ por 5 días (Sánchez-Yánez 2007).

Cinética de la degradación de LIREPATO por Aspergillus spp. y Penicillium spp. Para la cinética, del agar-LIREPATO se tomó el micelio de cada HML después de 5 días de incubación, para separar el micelio se añadió $15 \mathrm{~mL}$ de solución salinadetergente estéril $(12 \mathrm{~mL} \mathrm{NaCl} 0.85 \%$ y $3.0 \mathrm{~mL}$ detergente $0.01 \%$ ), luego se removió con asa y se recuperó la suspensión con pipeta estéril. Posteriormente se inocularon $12.5 \mathrm{~mL}$ de micelio de cada HML en matraces Erlenmeyer de $500 \mathrm{~mL}$ con 250 $\mathrm{mL}$ de caldo LIREPATO cuya composición $\left(\mathrm{g} \mathrm{L}^{-1}\right)$ fue: LIREPATO 10, peptona de caseína 5, extracto de levadura 1.3, $\mathrm{K}_{2} \mathrm{HPO}_{4} \quad 0.17, \mathrm{KH}_{2} \mathrm{PO}_{4}$ 2.61, $\mathrm{MgSO}_{4} 1.5, \mathrm{NaCl} 0.9, \mathrm{CuSO}_{4}$ 0.05, se adicionó azul de bromotimol $10 \mathrm{ppm}, 2.5 \mathrm{~mL}$ de solución detergente al $10 \%(\mathrm{p} / \mathrm{v})$, y $1 \mathrm{~mL} \mathrm{~L}^{-1}$ de solución de oligoelementos $\left(\mathrm{g} \mathrm{L}^{-1}\right): \mathrm{H}_{3} \mathrm{BO}_{3} 2.86, \mathrm{ZnSO}_{4}-7 \mathrm{H}_{2} \mathrm{O} \quad 0.22$, $\mathrm{MnCl}_{2}-7 \mathrm{H}_{2} \mathrm{O}$ 1.81, $\mathrm{KMnO}_{4} 0.09$, se ajustó el $\mathrm{pH}$ a 5.5 y se esterilizó a $121{ }^{\circ} \mathrm{C}$ durante $20 \mathrm{~min}$ (Sánchez-Yánez, 2007). Estos matraces se incubaron en aerobiosis en un agitador rotatorio por 28 días a $30{ }^{\circ} \mathrm{C}$ y $150 \mathrm{rpm}$. Se tomaron muestras a los 7, 14, 21, 28 días para medir la actividad Lac, LiP, $\mathrm{MnP}$, se incluyó un control con LIREPATO sin inocular con los HML.

Determinación del porcentaje de degradación de la LIREPATO por Aspergillus spp. y Penicillium spp. El porcentaje de degradación de LIREPATO por Aspergillus spp. y Penicillium spp. se determinó a los 28 días de incubación del caldo LIREPATO, para ello de separó el remanente o fase sólida por filtración con vacío, se lavó con agua destilada y se 
secó a $70{ }^{\circ} \mathrm{C}$ por $24 \mathrm{~h}$, se calculó el porcentaje de degradación de LIREPATO por pérdida de masa a peso constante.

Determinación de la actividad enzimática de la degradación de la LIREPATO por Aspergillus y Penicillium. El caldo LIREPATO degradado por las cepas de Aspergillus y Penicillium se centrifugó a $8000 \mathrm{rpm}$ a $4{ }^{\circ} \mathrm{C}$ por 15 min para eliminar el micelio. La actividad Lac se midió en espectrofotómetro (Hach DR 2500) mediante la oxidación del ácido 2.2'-acino-bis-(3-etil benzotiazolin-6-sulfónico) (A BTS) a $420 \mathrm{~nm}, 25^{\circ} \mathrm{C}$, con un coeficiente de extinción molar de $420=36000 \mathrm{M}^{-1} \mathrm{~cm}^{-1}$, se preparó una mezcla de reacción con $2.4 \mathrm{~mL}$ de buffer acetato de sodio $25 \mathrm{mM}$, pH 3.0, 300 L de ABTS $10 \mathrm{mM}$ y 300 L de la muestra (Palmieri et al. 1997, Ibrahim et al. 2011). La LiP se midió en espectrofotómetro (UV-Vis Thermo Scientific Evolution 60S) mediante la oxidación de alcohol veratrílico a veratrilaldehído a $310 \mathrm{~nm}, 25^{\circ} \mathrm{C}$ y coeficiente de extinción molar de $310=9300 \mathrm{M}^{-1} \mathrm{~cm}^{-1}$, se preparó la mezcla de la reacción con $2.5 \mathrm{~mL}$ de buffer tartrato de sodio $100 \mathrm{mM}, \mathrm{pH} 3.0,1 \mathrm{~mL}$ de alcohol veratrílico 10 $\mathrm{mM}, 400$ L de la muestra centrifugada y $100 \mathrm{~L}$ de $\mathrm{H}_{2} \mathrm{O}_{2} 10 \mathrm{mM}$. La MnP se midió por la formación de tartrato $\mathrm{Mn}^{+3}$ a $240 \mathrm{~nm}, 25^{\circ} \mathrm{C}$ y un coeficiente de extinción molar del $240=6500 \mathrm{M}^{-1} \mathrm{~cm}^{-1}$, se preparó la mezcla de reacción con $3.4 \mathrm{~mL}$ de buffer malonato de sodio $50 \mathrm{mM}, \mathrm{pH} 4.5,0.1 \mathrm{~mL}$ de $\mathrm{MnSO}_{4} 15$ $\mathrm{mM}, 400 \mathrm{~L}$ de la muestra centrifugada y $100 \mathrm{~L}$ $\mathrm{H}_{2} \mathrm{O}_{2} 10 \mathrm{mM}$ (Gao et al. 2011).

Determinación de aromáticos de la degradación de la LIREPATO por Aspergillus spp. y Penicillium spp. A partir de caldo LIREPATO donde crecieron los HML se tomaron $5 \mathrm{~mL}$ que se centrifugaron a $8000 \mathrm{rpm} / 15 \mathrm{~min}$, el sobrenadante se ajustó a pH 2 13 con $\mathrm{HCl}$ concentrado (37\% p/p), se agregó $\mathrm{NaCl}$ a saturación y $5 \mathrm{~mL}$ de acetato de etilo concentrado para la extracción de los aromáticos. Entonces se inyectó $1 \mu \mathrm{l}$ de muestra en el cromatógrafo de gases (Varian CP-3800), equipado con una columna capilar de fenil-metilpolisiloxano de $30 \mathrm{~m}$ x $0.53 \mathrm{~mm}$, el gas acarreador $\mathrm{N}_{2}$ se mantuvo con un flujo de 35 $\mathrm{mL} / \mathrm{min}$; la temperatura del horno, inyector y detector FID fueron de 90,270 y $300{ }^{\circ} \mathrm{C}$, respectivamente. Se usó como patrón una mezcla estándar de los ácidos hidroxibenzoico, vainillínico, ferúlico y siríngico, así como de vainillina y guayacol en concentración de $1 \mathrm{mg} / \mathrm{mL}$ disueltos en acetato de etilo (Wu et al. 1987, Valenciaga et al. 2009).

El diseño experimental fue completamente aleatorio y empleo 5 tratamientos: cuatro hongos más un control sin inocular, con tres replicas por tratamiento. Los datos experimentales se analizaron por Tukey con un nivel de significancia del $5 \%$ con el software de estadística JMP 11.0 Statistical Analysis System SAS ${ }^{\circledR}$.

\section{Resultados}

Porcentaje de degradación de la LIREPATO por Aspergillus y Penicillium. La cepa de P. chrysogenum AT4 en concentración de $10 \mathrm{~g} \mathrm{~L}^{-1}$ de LIREPATO mostró el mayor por ciento de degradación con un rendimiento de $34.8 \%$ a 28 días de incubación, en tanto A. fumigatus AT11 en la misma condición alcanzó un $29.1 \%$, ambos porcentajes de degradación fueron estadísticamente diferentes con una significancia del 5\%, comparados con los valores de P. chrysogenum AT3 y A. tubigensis AT12 (Tabla $1)$. 
Tabla 1. Porcentaje de degradación de lignina residual de paja de trigo por cepas de Aspergillus y Penicillium

\begin{tabular}{lcc}
\hline Ascomiceto & Degradación (\%) & $\begin{array}{c}\text { Análisis } \\
\text { estadístico }\end{array}$ \\
\hline Penicillium chrysogenumAT4 & $34.8 \pm 2.26$ & $\mathrm{a}$ \\
Aspergillus fumigatus AT11 & $29.1 \pm 0.74$ & ab \\
Penicillium chrysogenum AT3 & $23.3 \pm 0.92$ & $\mathrm{~b}$ \\
Aspergillus tubigensis AT12 & $16.1 \pm 1.36$ & $\mathrm{c}$ \\
Control & $0.0 \pm 0.00$ & $\mathrm{~d}$ \\
\hline
\end{tabular}

Las letras indican diferencia estadísticamente significativa para la actividad enzimática para cada semana de medición con un nivel de significancia $\alpha=0.05$.

\section{Actividad enzimática de Aspergillus y Penicillum} en la degradación de LIREPATO. La cepa de $P$. chrysogenum AT4 indujo la Lac desde la primera semana con una máxima de actividad de $111 \mathrm{U} \mathrm{L}^{-1}$, valor estadísticamente superior a las cepas de Aspergillus con un nivel de significancia del $5 \%$.

Figura 1 Cinética de la actividad enzimática de Aspergillus spp y Penicillium spp en la degradación de lignina residual de paja de trigo (LIREPATO). Las líneas verticales corresponden a la desviación estándar de tres mediciones. Nivel significancia $\alpha=0.05$.
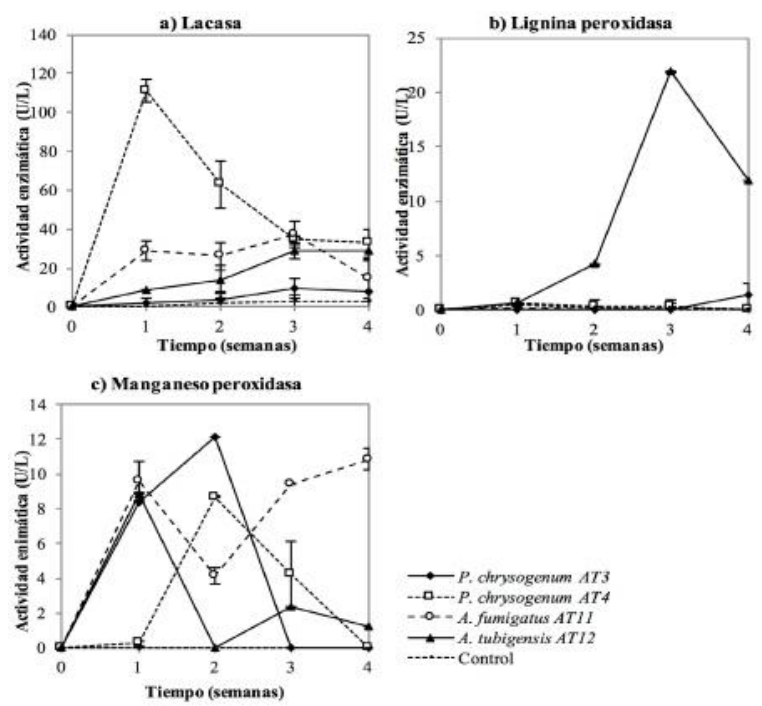

En tanto que sólo A. tubigensis AT12 generó la LiP entre la semana 2 a la 4 con un valor máximo de 21.9 $\mathrm{U} \mathrm{L}^{-1}$ a los 21 días de incubación. Entre tanto las cepas de Aspergillus spp. como Penicillium spp. sintetizaron la MnP con un tiempo de inducción de una semana; mientras que A. fumigatus AT11 alcanzó una máxima actividad de $10.9 \mathrm{U} \mathrm{L}^{-1}$ con un tiempo de generación de la enzima entre la segunda y tercera semana de incubación (Figura 1).

Figura 2 Cinética de la síntesis de aromáticos por Aspergillus spp. y Penicillium spp. en la degradación de LIREPATO. No se detectaron aromáticos en los matraces control sin inocular. Nivel significancia $\alpha=0.05$.
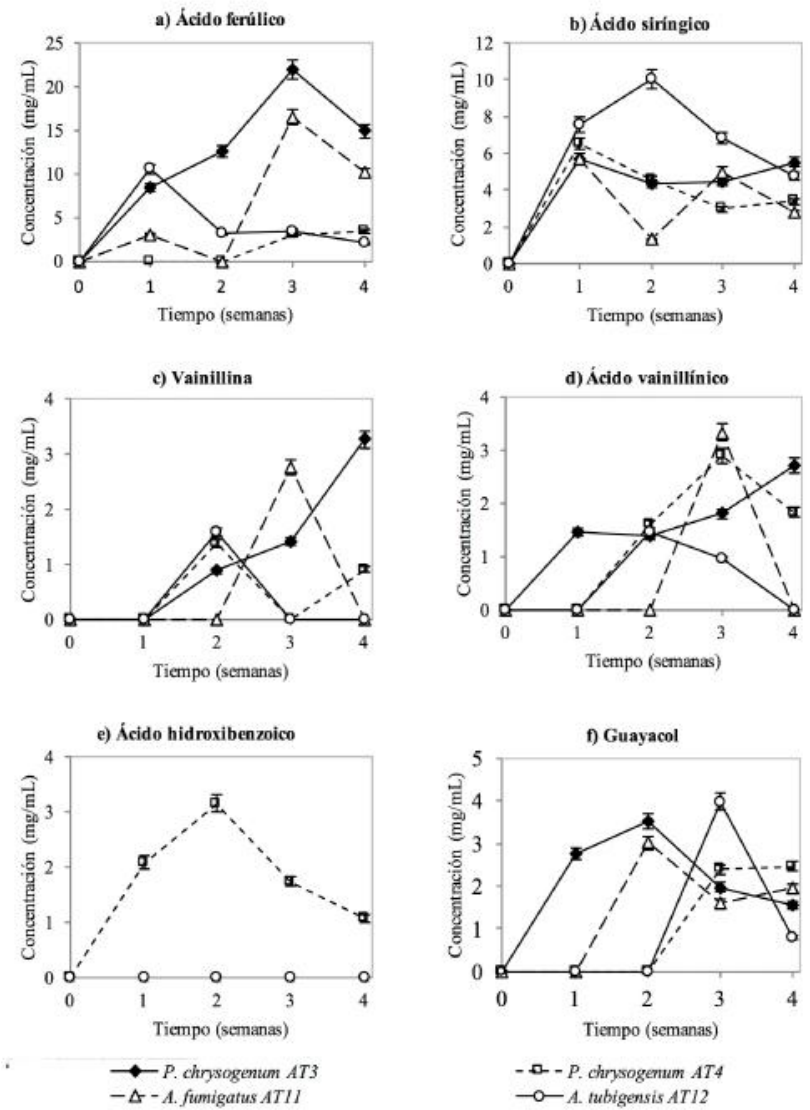

Síntesis de aromáticos por Aspergillus y Pencillium a partir de LIREPATO. Las cepas de Aspergillus y Penicillum degradaron la LIREPATO para la síntesis de aromáticos, de los cuales se identificaron 6 monómeros: P. chrysogenum AT3 generó hasta 21.9 $\mathrm{mg} / \mathrm{mL}$ de ácido ferúlico en la semana 3 , fue el aromático que se produjo en mayor concentración. A. tubigensis AT12 generó $10.1 \mathrm{mg} / \mathrm{mL}$ de ácido 
siríngico en la semana 2, A. fumigatus AT11 3.3 $\mathrm{mg} / \mathrm{mL}$ de ácido vainillínico en la semana 3 , mientras que $P$. chrysogenum AT3 hasta $3.3 \mathrm{mg} / \mathrm{mL}$ de vainillina en la semana 4. $P$. chrysogenum AT4 fue el único que produjo ácido hidroxibenzoico con 3.2 $\mathrm{mg} / \mathrm{mL}$ de en la semana 2 mientras que $P$. chrysogenum AT3 hasta $3.5 \mathrm{mg} / \mathrm{mL}$ de guayacol en la semana 3 (Figura 2).

\section{Discusión}

En relación al por ciento de degradación de la LIREPATO por las cepas Aspergillus y Penicillium se registró un valor similar a lo reportado en basidiomicetos, en una concentración relativamente alta de LIREPATO de $10 \mathrm{~g} \mathrm{~L}^{-1}$ en un periodo de tiempo relativamente corto de 28 días, lo que les constituye como una alternativa interesante para explotación de residuos agrícolas ricos en lignina. Por ejemplo $P$. chrysogenum AT4 degradó el 34.8\% de la LIREPATO, en contraste con lo reportado en Phlebia brevispora y Ceriporiopsis subvermispora con $20 \mathrm{~g}$ $\mathrm{L}^{-1}$ de paja de trigo y $25 \mathrm{~mL}$ de extracto de malta $0.05 \%$ alcanzaron un 30.5 y $23 \%$ degradación respectivamente en 30 días (Arora \& Sharma 2009, Arora et al. 2011), así como con Phanerochaete chrysosporium que con $20 \mathrm{~g} \mathrm{~L}^{-1}$ de paja de trigo y $25 \mathrm{~mL}$ de extracto de malta $0.05 \%$ registró un por ciento de degradación del 30\% en 21 días (Singh et al. 2011), Sin embargo el mismo basidiomiceto con $2 \mathrm{~g} \mathrm{~L}^{-1}$ de paja de trigo, $0.1 \%$ de polisorbato alcanzó un 25\% en 7 días (Zeng et al. 2011) mientras que Trametes versicolor con $2 \mathrm{~g} \mathrm{~L}^{-1}$ de paja de trigo más 40 de glucosa, $2.8 \mathrm{~mL} \mathrm{~L}^{-1}$ de aceite de soya, se registró un $46 \%$ en 21 días de cultivo (Salvachúa et al. 2011). Aunque las pajas utilizadas en estos experimentos no sometieron a tratamiento previo para eliminar celulosas y hemicelulosas.

15
Tanto Aspergillus como Penicillium tuvieron tiempos de generación relativamente corto comparados con los basidiomicetos reportados en la literatura, ya que mostraron una rápida inducción de la actividad enzimática para la degradación de la LIREPATO; en promedio de 7 días, un tiempo menor, a los 14 días reportados en otras investigaciones relacionadas con basidiomicetos (Salvachúa et al. 2011, Zeng et al. 2011) (Tabla 2).

El menor periodo de tiempo de inducción de la actividad enzimática se detectó a la semana de crecimiento en $P$. chrysogenum AT4 con un valor de la actividad Lac de $111 \mathrm{U} \mathrm{l}^{-1}$ en 7 días, cantidad relativamente alta comparada con Phanerochaete fascicularia que con $85 \mathrm{~g} \mathrm{~L}^{-1}$ de paja de trigo, 10 de glucosa y 5 de extracto de levadura, alcanzó $80 \mathrm{U} \mathrm{L}^{-1}$ en 12 días de incubación (Arora et al. 2002), similar a la cepa Euc-1 que con $15 \mathrm{~g} \mathrm{~L}^{-1}$ de paja de trigo más $0.05 \mathrm{~g} \mathrm{~L}^{-1}$ de glucosa; registró la máxima actividad Lac de $100 \mathrm{U} \mathrm{L}^{-1}$ en 46 días de incubación (Dias et al. 2010), similar a lo reportado en Phlebia rufa y Ganoderma applanatum que con $15 \mathrm{~g} \mathrm{~L}^{-1} \mathrm{de}$ paja de trigo más $0.05 \mathrm{~g} \mathrm{~L}^{-1}$ de glucosa mostró 140 , $350 \mathrm{U} \mathrm{L}^{-1}$ respectivamente a los 7 días de incubación (Dinis et al. 2009). En estas investigaciones el medio de cultivo empleado para la degradación de las pajas se enriqueció con glucosa, factor nutricional considerado necesario para inducir la actividad enzimática en los basidiomicetos, sin embargo esta investigación se demostró que no indispensable enriquecer el medio de cultivo con fuente de carbono adicional a la LIREPATO para su degradación y formación de aromáticos. 
Tabla 2 Comparativo de reportes de actividad enzimática en hongos degradadores de lignina

\begin{tabular}{|c|c|c|c|c|c|c|c|c|}
\hline $\begin{array}{l}\text { Basidiomiceto } \\
\text { (género especie) }\end{array}$ & $\begin{array}{c}\text { Actividad máxima } \\
\text { (U/L)/ } \\
\text { Tiempo } \\
\text { (días) }\end{array}$ & $\begin{array}{l}\text { Fuente de lignina } \\
(\mathrm{g} / \mathrm{L})\end{array}$ & $\begin{array}{l}\text { Fuente } C \\
\text { adicional } \\
\quad(\mathrm{g} / \mathrm{l})\end{array}$ & Fuente N (g/l) & $\begin{array}{l}\text { Factor creci- } \\
\text { miento }(\mathrm{g} / \mathrm{l})\end{array}$ & $\begin{array}{l}\text { Cobre } \\
(\mathrm{Cu})(\mathrm{g} / \mathrm{l})\end{array}$ & $\begin{array}{l}\text { Degradación } \\
(\%)\end{array}$ & Referencia \\
\hline Phellinus robustus & $\frac{3.3 \mathbf{U ~ g}^{-1}}{7 \text { días }}$ & $\begin{array}{c}2 \\
\text { paja de trigo }\end{array}$ & $\begin{array}{c}\text { Glucosa } \\
\text { (40) } \\
\text { Almidón } \\
(26.3)\end{array}$ & $\left(\mathrm{NH}_{4}\right)_{2} \mathrm{SO}_{4}(9)$ & NE & NE & $\begin{array}{l}36 \% \text { en } 21 \\
\text { días }\end{array}$ & $\begin{array}{l}\text { Salvachúa et al. } \\
\qquad \text { (2011) }\end{array}$ \\
\hline cepa Euc-T1 & $\frac{\mathbf{1 0 0 \mathbf { ~ U ~ } ^ { - 1 }}}{46 \text { días }}$ & $\begin{array}{c}15 \\
\text { paja de trigo }\end{array}$ & $\begin{array}{c}\text { Glucosa } \\
(0.05)\end{array}$ & NE & $\mathrm{NE}$ & NE & $80 \%, 46$ días & Dias et al. (2010) \\
\hline Trametes versicolor & $\frac{140 \mathbf{~ U ~ l}^{-1}}{30 \text { días }}$ & $\begin{array}{c}5 \\
\text { paja de trigo }\end{array}$ & NE & $\mathrm{NE}$ & $\mathrm{NE}$ & $\mathrm{NE}$ & ND & $\begin{array}{l}\text { Rodrigues et al. } \\
\text { (2007) }\end{array}$ \\
\hline Ganoderma applanatum & $\frac{\mathbf{3 5 0} \mathbf{U ~ l}^{-1}}{7 \text { días }}$ & $\begin{array}{c}15 \\
\text { paja de trigo }\end{array}$ & $\begin{array}{c}\text { Glucosa } \\
(0.05)\end{array}$ & $\mathrm{NE}$ & $\mathrm{NE}$ & $\mathrm{NE}$ & ND & Dinis et al. (2009) \\
\hline Phlebia fascicularia & $\frac{\mathbf{8 5 0 0}{\mathbf{U ~} \mathbf{~ l}^{-1}}^{12 \text { días }}}{1}$ & $\begin{array}{c}8 \\
\text { paja de trigo }\end{array}$ & $\begin{array}{l}\text { Glucosa } \\
\quad(10)\end{array}$ & $\begin{array}{l}\text { Peptona } \\
\text { (5) }\end{array}$ & $\begin{array}{l}\text { Extracto de } \\
\text { levadura } \\
\text { (5) }\end{array}$ & NE & ND & Arora et al. (2002) \\
\hline $\begin{array}{c}\text { Penicillium. chrysoge- } \\
\text { num }\end{array}$ & $\frac{111 \mathrm{U} \mathrm{I}^{-1}}{7 \text { días }}$ & $\begin{array}{c}10 \\
\text { lignina semipuri- } \\
\text { ficada de paja de } \\
\text { trigo }\end{array}$ & 0 & $\begin{array}{l}\text { Peptona } \\
\text { (5) }\end{array}$ & $\begin{array}{l}\text { Extracto de } \\
\text { levadura } \\
\text { (5) }\end{array}$ & $\begin{array}{c}\mathrm{CuSO}_{4} \\
0.05\end{array}$ & $\begin{array}{l}34.8 \% \text { en } 28 \\
\text { días }\end{array}$ & Esta investigación \\
\hline
\end{tabular}

ND: No determinado, NE: No especificado.

La cepa de A. tubigensis AT12 indujo la LiP; enzima ausente en la mayoría de los géneros de HML (Dashtban et al. 2010), por lo que su detección en esta cepa, es de interés en la investigación para optimitización de la degradación de la LIREPATO. En las cepas de Aspergillus y Penicillium la actividad MnP no fue importante comparada con la reportada para basidiomicetos (Fujian et al. 2001, Dinis et al. 2009), lo anterior sugiere que al menos en las cepas de la presente investigación; la MnP podría no ser necesaria para la degradación de la LIREPATO en aromáticos. En contraste, la elevada actividad Lac de las cepas de Aspergillus y Penicillium comparada con lo reportada para los basidiomicetos, sugiere que esta enzima podría ser fundamental para la degradación de la LIREPATO en aromáticos (Dashtban et al. 2010), y que la LiP y la MnP tienen un papel secundario en este proceso, lo que es necesario dilucidar con precisión.

Las cepas de Aspergillus y Penicillium con actividad Lac alta, mostraron la mayor generación de aromáticos, puesto que se detectó que $A$. tubigensis
AT12 generó la mayor concentración de ácido siríngico. En contraste se sugiere que la actividad LiP y MnP podría estar relacionada con la síntesis de una amplia variedad de estos compuestos.

De acuerdo con los resultados señalados, fue evidente que las cepas de Aspergillus y Penicillium para la degradación de la LIREPATO en aromáticos tuvieron necesidades nutricionales mínimas, comparadas con lo reportado en los basidiomicetos. Por principio las cepas de la presente investigación degradaron una concentración relativamente alta de LIREPATO de $10 \mathrm{~g} \mathrm{~L}^{-1}$; una ventaja para su explotación como materia prima de bajo costo, para la producción de aromáticos en un medio de cultivo simple sin enriquecer con glucosa como fuente de carbono adicional, en contraste con los basidiomicetos que según la literatura si la requieren. Mientras que el periodo de inducción de la lacasa de estas cepas fue menor al reportado para los basidiomicetos para la degradación de la lignina.

Aunque existen diversas investigaciones sobre el uso de los componentes carbonados de los residuos 
agrícolas, la lignina por su recalcitrancia es un compuesto remanente de su degradación, en consecuencia en la literatura existen escasas propuestas para su explotación en biotecnología. Por tanto los resultados obtenidos en esta investigación apoyan la aplicación de cepas de Aspergillus y Penicillium para la degradación de la LIREPATO en aromáticos de valor biotecnológico, como una alternativa competitiva al empleo convencional de los basidiomicetos.

\section{Conflictos de intereses}

Los autores declaran que no existen conflictos de interés.

\section{Agradecimientos}

Al Proyecto 150001 SENER-CONACYT, al CONACYT por la BECA 239180 para el primer autor, a los proyectos 2.7 y 5.15 (2016) de la Coordinación de la Investigación Científica de la UMSNH, Morelia, Mich, México.

\section{Literatura citada}

Arora DS, Sharma RK. Comparative ligninolytic potential of Phlebia species and their role in improvement of in vitro digestibility of wheat straw. J Anim Feed Sci. 2009; 18(2009): 151161.

Arora DS, Sharma RK, Chandra P. Biodelig nification of wheat straw and its effect on in vitro digestibility and antioxidant properties. Int Biodeter Biodegr. 2011; 65(2): 352-358.

Arora DS, Chander M, Gill PK. Involvement of lignin peroxidase, manganese peroxidase and laccase in degradation and selective ligninolysis of wheat straw. Int Biodeter Biodegr. 2002; 50(2): 115-120.

Buranov AU, Mazza G. Lignin in straw of herbace ous crops. Ind Crop Prod. 2008; 28(3): 237-259.

Chang A, Fan J, Wen X. Screening of fungi capable of highly selective degradation of lignin in rice straw. Int Biodeter Biodegr. 2012; 72: 26-30.

Dashtban M, Schraft H, Syed TA, Qin W. Fungal biodegradation and enzymatic modification of lignin. Int J Biochem Mol Biol. 2010; 1(1): 3650.

Dekker RFH, Barbosa AM, Sargent K. The effect of lignin-related compounds on the growth and production of laccases by the ascomycete, Botryosphaeria sp. Enzyme Microb Technol. 2002; 30(3): 374-380.

Dias AA, Freitas GS, Marques GSM, Sampaio A, Fraga IS, Rodrigues MAM, et al. Enzymatic saccharification of biologically pre-treated wheat straw with white-rot fungi. Bioresour Technol. 2010; 101(15): 6045-6050.

Dinis MJ, Bezerra RMF, Nunes F, Dias AA, Guedes CV, Ferreira LMM, et al. Modification of wheat straw lignin by solid state fermentation with white-rot fungi. Bioresour Technol. 2009; 100(20): 4829-4835.

FAO. FAOSTAT [Database Internet]. Food and Agriculture Organization of the United Nations [2012]. Disponible en: http://faostat.fao.org.

Ferraz A, Durán N. Lignin degradation during softwood decaying by the ascomycete Chryso nilia sitophila. Biodegradation. 1995; 6(4): 265 274.

Fujian X, Hongzhang C, Zuohu L. Solid-state pro duction of lignin peroxidase (LiP) and manga nese peroxidase $(\mathrm{MnP})$ by Phanerochaete chry sosporium using steam-exploded straw as 
substrate. Bioresour Technol. 2001; 80(2): 149151.

Gao H, Wang Y, Zhang W, Wang W, Mu Z. Isolation, identification and application in lignin degradation of an ascomycete GHJ4. Afr J Biotechnol. 2011; 10(20): 4166-4174.

Ibrahim V, Mendoza L, Mamo G, Hatti-Kaul R. Blue laccase from Galerina sp.: properties and potential for Kraft lignin demethylation. Process Biochem. 2011; 46(1): 379-384.

Kim S, Dale B. Global potential bioethanol produc tion from wasted crops and crop residues. Biomass Bioenerg. 2003; 26(4): 361-375.

Li LJ, Wang Y, Zhang Q, Li JX, Yang XG, Jin J. Wheat straw burning and its associated impacts on Beijing air quality. Sci China Ser D. 2008; 51(3): 403-414.

Martínez ÁT, Speranza M, Ruíz-Dueñas FJ, Ferre ira $\mathrm{P}$, Camarero S, Guillén F, et al. Biodegra dation of lignocellulosics: microbilogical, chemi cal, and enzymatic aspects of the fungal attack of lignin. Int Microbiol. 2005; 8: 195-204.

Palmieri G, Giardina P, Bianco C, Scaloni A, Capa sso A, Sannia G. A Novel White Laccase from Pleurotus ostreatus. J Biol Chem. 1997; 272(50): 31301-31307.

Quéméneur M, Bittel M, Trably E, Dumas C, Fourage L, Ravot G, et al. Effect of enzyme addi tion on fermentative hydrogen production from wheat straw. Int J Hydrogen Energ. 2012; 37 (14): 10639-10647.

Quintero-Núñez M, Moncada-Aguilar A. Contami nación y control de las quemas agrícolas en Impe rial, California, y Mexicali, Baja California. Reg Soc. 2008; 20(43): 3-24.

Rodrigues MAM, Pinto P, Bezerra RMF, Dias AA, Guedes CVM, Cardoso VMG, et al. Effect of enzyme extracts isolated from white-rot fungi on chemical composition and in vitro digestibility of wheat straw. Anim Feed Sci Technol. 2007; 141(3-4): 326-338.

Safari-Sinegani A, Emtiazi G, Hajrasuliha S, Sharia tmadari H. Biodegradation of some agricultural residues by fungi in agitated submerged cultures. Afr J Biotechnol. 2005; 4(10): 1058-1061.

Salvachúa D, Prieto A, López-Abelairas M, LuChau T, Martínez Á, Martínez M. Fungal pretrea tment: An alternative in second-generation etha nol from wheat straw. Bioresour Technol. 2011; 102(16): 7500-7506.

Sánchez-Yánez JM. Breve Tratado de Microbio logía Agrícola Teoría y Práctica. Morelia, Micho acán México: Corporativo de Desarrollo Susten table, Centro de Investigación y Desarrollo de Michoacán, Universidad Michoacana de San Nicolás de Hidalgo, Secretaria de Desarrollo Rural en Michoacán; 2007. p. 130-133.

Sánchez C. Lignocellulosic residues: biodegradation and bioconversion by fungi. Biotechnol Adv. 2009; 27(2): 185-194.

Singh D, Zeng J, Laskar DD, Deobald L, Hiscox $\mathrm{WC}$, Chen S. Investigation of wheat straw biode gradation by Phanerochaete chrysosporium. Biomass Bioenerg. 2011; 35(3): 1030-1040.

Talebnia F, Karakashev D, Angelidaki I. Production of bioethanol from wheat straw: An overview on pretreatment, hydrolysis and fermentation. Bioresour Technol. 2010; 101(13): 4744-4753.

Tuyen VD, Cone JW, Baars JJB, Sonnenberg ASM, Hendriks WH. Fungal strain and incubation period affect chemical composition and nutrient availability of wheat straw for rumen fermen tation. Bioresour Technol. 2012; 111: 336-342.

Valenciaga D, Herrera RS, Simoes EOd, Chongo B, Torres V. Composición monomérica de la lig nina de Pennisetum purpureum vc. Cuba CT-115 
y su variación con la edad de rebrote. Rev Cubana Cienc Agr. 2009; 43(3): 315-319.

Widsten P, Kandelbauer A. Laccase applications in the forest products industry: A review. Enzyme Microb Tech. 2008; 42(4):293-307.

Wu FJ, Moreno J, Vela GR. Growth of Azotobacter vinelandii on soil nutrients. Appl Environ Micro biol. 1987; 53(3): 489-494.

Xu F, Sun J-X, Sun RC, Fowler P, Baird MS. Com parative study of organosolv lignins from wheat straw. Ind Crop Prod. 2006; 23(2): 180-193.
Zeng G, Yu H, Huang H, Huang D, Chen Y, Huang $\mathrm{G}$, et al. Laccase activities of a soil fungus Peni cillium simplicissimum in relation to lignin degradation. World J Microbiol Biotechnol. 2006; 22(4): 317-324.

Zeng J, Singh D, Chen S. Biological pretreatment of wheat straw by Phanerochaete chrysosporium supplemented with inorganic salts. Bioresour Technol. 2011; 102(3): 3206-3214. 